\title{
Climate change risks and mitigating measures of freshwater aquaculture in unmanaged ponds of Kaushambi district U.P.
}

\author{
Yogesh Mishra*
}

Department of Zoology Bhavan's Mehta Mahavidyalaya Bharwari Kaushambi Uttar Pradesh, India.

Publication history: Received on 12 November 2020; revised on 22 November 2020; accepted on 26 November 2020

Article DOI: https://doi.org/10.30574/gscbps.2020.13.2.0385

\begin{abstract}
The purpose of the study is to identify various climatic change risks encountered by fish farmers while doing freshwater aquaculture in the unmanaged ponds of district kaushambi Uttar Pradesh. The various climate change risks which were faced by rural farmers of Kaushambi are water quality, flooding of ponds, less rain, heavy mortality of fishes, planktonic collapse, long dry spells, disease outbreak, destruction of embankments etc. The study also includes the measures to encounter these risks. To maintain the quality of water the farmers have used lime, manure, alum, $\mathrm{KMnO4}$, salt and exchange of water. To control the flooding of ponds the farmers raises embankments by bamboo fencing with net. They have filled their ponds with pumps from canals / rivers and tube well water to face the problem of less rain and long dry spells. To avoid the heavy mortality of the fishes they have used early harvest, liming, shading and water movement by beating of water for oxygenation. To overcome with the planktonic collapse the farmers have used cow dung, gobar gas slurry, use of khari, choker in the water and exchange of 50 percent water. To control the disease outbreak the farmers have adopted lime, $\mathrm{KMnO4}$, medicines, neem leaves, banana stem etc.
\end{abstract}

Keywords: Flooding of ponds; Embankments; Disease outbreak; Mortality; Early harvest; Liming

\section{Introduction}

Climate change is one of the greatest concerns of everyone as it poses potential threat to environment and agricultural activities throughout the world. Adverse effects of climate change continue to be a major threat to rural livelihood (IPCC 2007a, 2007b; Nhemachena 2009; Pauliotte, Smit and Westerhoff 2009). Developing countries are generally considered more vulnerable to the effects of climate change than that of the developed countries. Fisheries and aquaculture are threatened by changes in the earth atmosphere and ocean, such as increasing global surface temperature, rising sea levels, increases in incident of UV radiation, irregular changes in average annual precipitation and increases in the variability and intensity of extreme weather events. The majority of the world's 200 million full and part-time fisher folk (fishers, fish processors, traders and ancillary workers) and their dependents live in areas vulnerable to human induced climate change or depend for a major part of their livelihood on resources whose distribution and productivity are known to be influenced by climate variation. Climate change affects fisheries and aquaculture via acidification, changes in sea temperatures and circulation patterns, the frequency and severity of extreme events, and sea-level rise and associated ecological changes. Both direct and indirect impacts include impact on targeted populations range and productivity, habitats and food webs as well as impacts on fishery and aquaculture cost, productivity and fisherman community livelihoods and safety (Daw et al., 2009; Badjeck et al, 2010).

Every unmanaged aquatic environment behaves in its own way, having their particular peak and lean seasons of hydro biological parameters. Inland fish consumption more suits to consumers of developing and under developed countries

${ }^{*}$ Corresponding author: Mishra Yogesh

Department of Zoology Bhavan's Mehta Mahavidyalaya Bharwari Kaushambi Uttar Pradesh, India.

Copyright (c) 2020 Author(s) retain the copyright of this article. This article is published under the terms of the Creative Commons Attribution Liscense 4.0. 
due to their less disposable income for consuming inland fish over marine one (FA0,2014). According to one of the report of CSO-MFS (2011), Inland fisheries enjoys prime of place in Indian economy. It provides employment and livelihood for fishers who solely depend on it.

In the different regions of Kaushambi district of UP the inland fish production has been carried out through ponds and tanks. Production through ponds and tanks reflect their entrepreneurial attitude for inland fish production. Almost all labour forces in agriculture are unorganized where as 98.7 percent unorganized labour is dwelling in fishing sector. Even fish farmers were inefficient in the application of production resources, the low output prices and the imperfect condition of input markets hampered efficient utilization of production inputs (Inoni OE, 2007), Rahman et al (2015) pointed out that fish seed and labour were underutilized in freshwater production system whereas fish seeds, labour and area were under used in wastewater fish production system. Similarly in another study by Akenbor and Ike (2015) revealed that pond size, fingerlings feed and fixed cost of items were underutilized while labour and operating cost were over utilized. Coefficient of human labour, feed, cow dung and manure had significant impact on gross return, whereas coefficient of feed, her harvesting and making sanctuary had significant impact on gross return of Beel fish farming (Uddin \&Farjana 2012). Looking into producers' prospective profitability analysis of inland fishery is very much essential to be determined and resource use efficiently ads substances in the direction of productivity. That's why this study adhered with two basic objectives i.e. to estimate the climate change risks and to study subsequent resource use efficiency in inland fish production. Kaushambi district is situated in between Ganga and Yamuna River. It plays a very pivotal role in the agriculture of the district. The principal source of irrigation is canals and tube wells. District Kaushambi is bestowed with many water resources of rivers and canals, tanks, lakes and ponds. The major inland fish production has been carried out through ponds and tanks. Production through ponds and tanks reflect their entrepreneurial attitude for inland fish production. There were more than 8000 pond in government record of district Kaushambi. About 150 ponds have been missed now. The areas of most ponds are now reduced. They are occupied by residents of Kaushambi. The farming is taken on most of the ponds.

\section{Material and methods}

The study was conducted for a period of 12 months (July 2018 to June 2019). A simple random sample of 100 fish farmers were selected from 7 blocks of district Kaushambi, UP. The blocks which were selected for the study are Chail, Kada, Kaushambi, Muratganj, Nevada, Sarsawan and Sirathu. The fish farmers from each block were selected for the study (Table-1).

Table 1 Name of blocks and number of Fish farmers selected for the survey.

\begin{tabular}{|l|l|}
\hline Name of the blocks & No. Of fish farmers \\
\hline Chail & 25 \\
\hline Kada & 10 \\
\hline Kaushambi & 14 \\
\hline Muratganj & 10 \\
\hline Nevada & 11 \\
\hline Sarsawan & 18 \\
\hline Sirathu & 12 \\
\hline Total & 100 \\
\hline
\end{tabular}

A questionnaire was developed and administered to the fish farmers to obtain general information such as primary occupation, major source of income, age, qualification, family size, fish farming experiences and their farm details. All the farmers were interviewed whether they encountered any climatic change risk in relation to the fish farming. The fish farmers were facing various climate change risks. Generally in rural areas the ponds were old and unmanaged so they are not suitable for fish culture. The fish farmers were facing various climate change risks. They are categorised into 8 types such as (1) water quality (2) flooding of ponds (3) less rain (4) heavy mortality (5) planktonic collapse (6) long dry spells (7) disease outbreak and (8) destruction of embankments. 
Table 2 Frequency distribution of the fish farmers and various climate change risks.

\begin{tabular}{|l|l|}
\hline Various climate changes & No. Of fish farmers \\
\hline Water supply & 22 \\
\hline Flooding of ponds & 20 \\
\hline Less rain & 18 \\
\hline Heavy mortality & 04 \\
\hline Planktonic collapse & 08 \\
\hline Long dry spell & 12 \\
\hline Disease outbreak & 16 \\
\hline Total & 100 \\
\hline
\end{tabular}

\section{Results and discussion}

The fish farmers face various climate change risks while practicing pisciculture during the study period. The major climate related risks which are faced by farmers are water quality, flooding of ponds, less rain, heavy mortality, planktonic collapse, long dry spells, disease outbreak and destruction of embankments (Table- 2).The farmers were also asked about the possible solutions against the climate change risks (table- 3).

Out of 100 respondents, 22 farmers reported the risk of water quality. The farmers were adopted some common measures to maintain water quality. More than $90 \%$ farmers were used liming, water exchange, manuring, alum, $\mathrm{KMnO4}$, salt etc. (table- 3).

Table 3 Deterioration of water quality

\begin{tabular}{|l|l|c|}
\hline Measures adopted & No. of farmers & $\mathbf{\%}$ \\
\hline Use of lime & 7 & 31.82 \\
\hline Water exchange & 4 & 18.18 \\
\hline Liming and manuring & 2 & 9.09 \\
\hline Use of lime,alum,KMnO4 and salt & 2 & 9.09 \\
\hline Application of lime and cow dung & 2 & 9.09 \\
\hline Liming and netting & 2 & 9.09 \\
\hline Using lime and mahua oil cake & 2 & 9.09 \\
\hline Use of lime, urea and other medicine & 1 & 4.55 \\
\hline Total & 22 & 100 \\
\hline
\end{tabular}

Out of 100 respondents 20 farmers have also reported the risk of flooding of ponds. About $75 \%$ of farmers mention that they have adopted to overcome the problem of flooding. They have adopted measures such as use of bamboo screen, net screen, provision of inlet/outlet, raising of embankment etc. (table- 4)

Table 4 Flooding of ponds

\begin{tabular}{|l|l|c|}
\hline Measures adopted & No. of farmers & \% \\
\hline Water level maintained by inlet and outlet & 6 & 30.00 \\
\hline Bamboo screen with net fence & 5 & 25.00 \\
\hline Raising of embankment by bamboo fencing & 4 & 20.00 \\
\hline Use of net and pump & 3 & 15.00 \\
\hline Increasing in embankment area & 2 & 10.00 \\
\hline Total & 20 & 100 \\
\hline
\end{tabular}


In total, 18 respondents have reported the risk of less rain. Out of these farmers about $87 \%$ had adopted the measurers like filling with ground water, filling water with pump from canals/rivers, filled water from outside by pump, use of spring water, construction of deep tube well inlet and outlet etc. (table- 5)

Table 5 Less rain

\begin{tabular}{|l|l|l|}
\hline Measures adopted & No. of farmers & $\mathbf{\%}$ \\
\hline Filled with ground water & 6 & 33.33 \\
\hline Filled water with pump from canal/ river & 4 & 22.22 \\
\hline Filled water from outside by pump & 3 & 16.67 \\
\hline Use of spring water & 3 & 16.67 \\
\hline Construction of deep tube well inlet and outlet & 1 & 5.56 \\
\hline Others & 1 & 5.56 \\
\hline Total & 18 & 100 \\
\hline
\end{tabular}

Heavy mortality in aquaculture ponds of Kaushambi is rarely reported by farmers. Out of 100 farmers, only 4 have reported about heavy mortality. They have reported that when water is warmed in summer months of May and June most of the fishes were died. They are also having adopted some measures to control it. About all the farmers have adopted the measures of early harvest, liming, supply of water, movement of water etc. Some farmers have adopted shading on fish pond and water movement by beating water for oxygen generation and some farmers have applied medicines and $\mathrm{KMnO} 4$ solution (table- 6).

Table 6 Heavy mortality

\begin{tabular}{|l|l|l|}
\hline Measures adopted & No. of farmers & $\mathbf{\%}$ \\
\hline Early harvest & 1 & 20 \\
\hline Liming, supply of water and movement of water & 1 & 20 \\
\hline Shading of fish pond & 1 & 20 \\
\hline Water movement by beating for oxygen generation & 1 & 20 \\
\hline Application of medicines and KmnO4 & 1 & 20 \\
\hline Total & 5 & 100 \\
\hline
\end{tabular}

Planktonic collapse has been reported by 8 out of 100 farmers. About $37 \%$ of respondents reported that they have adopted manuring of cow dung/hen litter and gobar gas slurry, about 25\% of farmers have reported filling with fresh ground water and use of fertilizers. $25 \%$ of farmers also reported exchange of $50 \%$ of water (table- 7 ).

Table 7 Planktonic collapse

\begin{tabular}{|l|l|l|}
\hline Measures adopted & No. of farmers & $\mathbf{\%}$ \\
\hline Manuring ( cow dung/ hen litter & 3 & 37.5 \\
\hline Application of lime, cow dung and manure & 2 & 25.00 \\
\hline Filling with fresh groundwater and use of fertilizer & 2 & 25.00 \\
\hline Exchange of 50\% water & 2 & 25.00 \\
\hline Others & 1 & 25.00 \\
\hline Total & 10 & 100 \\
\hline
\end{tabular}

Out of 100 farmers, 12 farmers were reported about long dry spell. It was found that it was due to global warming. The global warming has affected fish farming in various ways. It has delayed the breeding season, reducing the culture period etc. To solve this problem the farmers have adopted many measures. About 33\% of the farmers have filled their 
ponds with ground water by bore well. About $25 \%$ of farmers were filled their ponds by canals. About $16 \%$ of the farmers have adopted use of tube well water. About $16 \%$ of the farmers have stopped fish culture and completely harvested fish and $8 \%$ farmers have constructed new reservoir (table- 8).

Table 8 Long dry spell

\begin{tabular}{|l|l|l|}
\hline Measures adopted & No. of farmers & $\mathbf{\%}$ \\
\hline Filling of ground water by bore well & 4 & 33.33 \\
\hline Filling water by canal & 3 & 25.0 \\
\hline Use of tube well water & 2 & 16.67 \\
\hline Fish culture shifted to agriculture & 2 & 16.67 \\
\hline Construction of reservoir & 1 & 8.33 \\
\hline Total & 12 & 100 \\
\hline
\end{tabular}

The disease outbreak is a major factor in fish farming. Almost all the fish farmers have reported some of the diseases in fish. Out of hundred farmers, 16 were faced some diseases in their ponds. They have adopted some safety measures to diseases. About 31\% of the farmers have dissolved lime in their ponds. About $25 \%$ of the farmers have uses $\mathrm{KMnO} 4$ solution in water. About $18 \%$ of the farmers have used medicines, $12 \%$ have uses neem leaves and $12 \%$ have uses other measures (table- 9)

Table 9 Disease outbreak

\begin{tabular}{|l|l|l|}
\hline Measures adopted & No. of farmers & \% \\
\hline Lime application & 5 & 31.25 \\
\hline Application of KmnO4 solution & 4 & 25.0 \\
\hline Application of medicines & 3 & 18.75 \\
\hline Use of neem leaves, but ox, banana stem and lime & 2 & 12.5 \\
\hline Others & 2 & 12.5 \\
\hline Total & 16 & 100 \\
\hline
\end{tabular}

\subsection{Factors influencing controlling measures}

All the farmers were influenced by many factors when they are adopting controlling measures. Amaru and Netra (2013), observed that stakeholder's knowledge of changing climate and associated impact is important for on-ground adaptation. Perceptions of farmers as well as fisheries administrators hold key to development of adaptive measures. Saha et al, (2015) advocated that the planning for aquaculture projects should focus not only on technical aspects but also due importance is to be given for the perception of practicing fish farmers. There are many factors which are faced by farmers to control the climatic factors. The cost of the controlling measures have affected more to the farmers as they have no much money to afford and manage their ponds properly. They have used very simple controlling measures which were effective to the ponds as well as to the nature. The farmers also adopted such measures which were available locally. Besides these measures the farmers were uses traditional knowledge of controlling measures against climatic risks.

\section{Conclusion}

The study has brought out in the unmanaged ponds of Kaushambi district by aquaculture fish farmers. The farmers were faced many climatic changes risks and tried to mitigate various measures. These measures they have adopted need to analyzed to develop more refined mitigation strategies. The methods they have applied would help other fish farmers where aquaculture is being practiced to make necessary preventive measures. Climate change would affect the 
livelihood of the farmer's. It also disturbs the infrastructure and economy of the farmers. So it is essential that fisheries and aquaculture sector are integrated into climate change adaptation and economic policies at the national level to ensure broader development planning. It was also noted that if the ponds were managed then the effects of climate can be reduced and the production of fish would be increased.

\section{Compliance with ethical standards}

\section{Acknowledgments}

The author expresses his indebtedness and heartfelt gratitude to Dr. D. N. Jha scientist ICAR- CIFRI Allahabad, ministry of agriculture, Govt. of India for their intellectual inputs and sophisticated guidance throughout the research work.

\section{Disclosure of conflict of interest}

The author declares that there is no conflict of interest

\section{Statement of informed consent}

Informed consent was obtained from all individual participants included in the study.

\section{References}

[1] IPCC (2007a) Impacts, Adaptation and Vulnerability. ML Parry, OF Canziani, JP Palutikof, PJ van der Linden, CE Hanson, Eds. Cambridge University Press, Cambridge, UK, 976 p. IPCC (2007b) Climate Change: Synthesis Report. Contribution of working group I, II and III to the Fourth Assessment Report of the Intergovernmental Panel on Climate Change. Geneva: Intergovernmental Panel on Climate Change Core Writing Team, Pachauri RK, Reisinger, (Eds.). IPCC, Geneva Switzerland (2007), 104.

[2] Nhemachena C Agriculture and Future Climate Dynamics in Africa: Impacts and Adaptation Options. Pretoria: University of Pretoria. Ph. D. Thesis (2009), 150.

[3] Pouliotte J, Westerhoff L. Adaptation and Development: Livelihood and climate change in Subarnabad, Bangladesh. Climate Change and Development (2009) 1: 31-46.

[4] Daw T, Adger WN Brown K, Badjeck MC. Climate changes and capture fisheries: potential impacts, adaptation and mitigation. In k. Cochrane, C. De Young, D Soto, T Bahri, eds. Climate change implications for fisheries and aquaculture: overview of current scientific knowledge, 107-150. FAO Fisheries and Aquaculture Technical (2009), 530. Rome, FAO. 212.

[5] FAO World Review of Fisheries and Aquaculture. State of World Fisheries and Aquaculture (2014) 1-10.

[6] CSO-MFS. Manual on Fishery statistics. Ministry of Statistics and Programme Implementation, Government of India (2011).

[7] Inoni OE. Allocative Efficiency in Pond Fish Production in Delta State Nigeria: A Production Function Approach. Agriculture Tropical Et Subtropica (2007), 40(4):127-134.

[8] Rahaman SKM, Ghosh A, Pal S, Nandi S. A comparison of resource use efficiency and constraint of wastewater and freshwater fish production system in West Bengal. Economic Affair (2015), 60(2): 249-255.

[9] Akenbor AS, Ike PC. Analysis of Technical Efficiency of Catfish Farming in Edo State, Nigeria. Journal of Biology, Agriculture and Healthcare (2015), 5(2): 96-101.

[10] Uddin MT, Farjana I. An Economic Study of Low Lying Fish Farming in Selected Areas of Kishoreganj District. Progressive Agriculture (2012), 23(1, 2): 81-90.

[11] Amaru S, Netra BC. Climate Adaptation: Institutional response to environmental constraints, and the need for increased flexibility, participation and integration of approaches. Applied Geography (2013), 39: 128-139.

[12] Saha GS, Radheshyam, HK De, K Kumar, PP Chakraborty, AS Mahapatra, N Panda. Perceptions of the farmers and fishery extension on climate change parameters affecting aquaculture. J Inland Fish Soc. India (2015), 47 (2):612. 


\section{Author's Short Biography}

Dr. Yogesh Mishra is a senior Assistant Professor of Zoology at Bhavan's Mehta Mahavidyalaya
Bharwari Kaushambi Uttar Pradesh, India since 2009. He received his Ph D in fishery science in
2013. He is a frequent speaker and attended / chaired in the national and international
conferences. He enjoys with nature, natural things and environment.

